\title{
Age- and Strain-Related Differences in Bone Microstructure and Body Composition During Development in Inbred Male Mouse Strains
}

\author{
Maria Papageorgiou ${ }^{1,2} \cdot$ Ursula Föger-Samwald $^{1} \cdot$ Katharina Wahl $^{1} \cdot$ Katharina Kerschan-Schindl $^{3}$. \\ Peter Pietschmann ${ }^{1}$ (D)
}

Received: 25 September 2019 / Accepted: 21 December 2019 / Published online: 4 January 2020

(c) The Author(s) 2020

\begin{abstract}
We explored age- and strain-related differences in bone microstructure and body composition in male C57BL/6J, DBA/2JRj and $\mathrm{C} 3 \mathrm{H} / \mathrm{J}$ mice. Bone microstructure of the femur, tibia and $\mathrm{L} 4$ was assessed by $\mu \mathrm{CT}$ at the age of 8,16 and 24 weeks. The weight of several muscles and fat depots were measured at the same time points. At all timepoints, $\mathrm{C} 3 \mathrm{H} / \mathrm{J}$ mice had the thickest cortices followed by DBA/2JRj and C57BL/6J mice. Nevertheless, C57BL/6J mice had higher Tb.BV/TV and Tb.N, and lower Tb.Sp than DBA/2JRj and C3H/J mice at least at 24 weeks of age. Skeletal development patterns differed among strains. C57BL/6J and DBA/2JRj mice, but not $\mathrm{C} 3 \mathrm{H} / \mathrm{J}$ mice, experienced significant increases in the sum of the masses of 6 individual muscles by 24 weeks of age. In C57BL/6J and DBA/2JRj mice, the mass of selected fat depots reached highest values at 24 weeks, whist, in $\mathrm{C} 3 \mathrm{H} / \mathrm{J}$ mice, the highest values of fat depots masses were achieved at 16 weeks. Early strain differences in muscle and fat masses were largely diminished by 24 weeks of age. C3H/J and C57BL/6J mice displayed the most favorable cortical and trabecular bone parameters, respectively. Strain differences in body composition were less overt than strain specificity in bone microstructure, however, they possibly influenced aspects of skeletal development.
\end{abstract}

Keywords Peak bone mass $\cdot$ Bone microstructure $\cdot$ Growth patterns $\cdot$ Body composition $\cdot$ Myostatin $\cdot$ Periostin

\begin{tabular}{|c|c|c|c|c|}
\hline \multicolumn{3}{|c|}{ Abbreviations } & Ct.Th & Average cortical thickness \\
\hline \multirow{3}{*}{\multicolumn{2}{|c|}{$\begin{array}{l}\text { ANOVA } \\
\text { ASBMR }\end{array}$}} & Analysis of variance & DXA & Dual-energy X-ray absorptiometry \\
\hline & & American Society for Bone and Mineral & EDL & M. extensor digitorum longus \\
\hline & & Research & ELISA & Enzyme-linked immunosorbent assay \\
\hline \multirow{4}{*}{\multicolumn{2}{|c|}{$\begin{array}{l}\text { BMC } \\
\text { BMD } \\
\text { Ct.Ar } \\
\text { Ct.Ar/Tt.Ar }\end{array}$}} & Bone mineral content & GAS & M. gastrocnemius \\
\hline & & Bone mineral density & GASP-1 & Growth and differentiation factor-associ- \\
\hline & & Cortical bone area & & ated serum protein 1 \\
\hline & & Cortical bone area fraction & HR-pQCT & $\begin{array}{l}\text { High-resolution peripheral quantitative } \\
\text { computed tomography }\end{array}$ \\
\hline \multirow{2}{*}{\multicolumn{3}{|c|}{$\begin{array}{l}\text { Electronic supplementary material The online version of this } \\
\text { article (https://doi.org/10.1007/s00223-019-00652-8) contains } \\
\text { supplementary material, which is available to authorized users. }\end{array}$}} & LTBP3 & $\begin{array}{l}\text { Latent transforming growth factor } \beta \text { bind- } \\
\text { ing protein } 3\end{array}$ \\
\hline & \multirow{3}{*}{\multicolumn{2}{|c|}{$\begin{array}{l}\text { Peter Pietschmann } \\
\text { peter.pietschmann@meduniwien.ac.at }\end{array}$}} & L4 & 4th Vertebral body \\
\hline \multirow[t]{2}{*}{$\triangle$} & & & L5 & 5th Vertebral body \\
\hline & & & QUAD & M. quadriceps femoris \\
\hline \multirow[t]{4}{*}{1} & \multirow{4}{*}{\multicolumn{2}{|c|}{$\begin{array}{l}\text { Department of Pathophysiology and Allergy Research, } \\
\text { Center for Pathophysiology, Infectiology and Immunology, } \\
\text { Medical University of Vienna, Waehringer Guertel 18-20, } \\
1090 \text { Vienna, Austria }\end{array}$}} & SE & Standard error \\
\hline & & & SOL & M. soleus \\
\hline & & & SPSS & Statistical package for the social sciences \\
\hline & & & TA & M. tibialis anterior \\
\hline \multirow[t]{3}{*}{2} & \multirow{3}{*}{\multicolumn{2}{|c|}{$\begin{array}{l}\text { Division of Bone Diseases, Department of Internal Medicine } \\
\text { Specialties, Faculty of Medicine, Geneva University } \\
\text { Hospital, Geneva, Switzerland }\end{array}$}} & Tb.BV/TV & Trabecular bone volume/tissue volume \\
\hline & & & Tb.N & Trabecular number \\
\hline & & & Tb.Th & Trabecular thickness \\
\hline 3 & $\begin{array}{l}\text { Departmen } \\
\text { Medical U }\end{array}$ & $\begin{array}{l}\text { f Physical Medicine and Rehabilitation, } \\
\text { ersity of Vienna, Vienna, Austria }\end{array}$ & Tb.Sp & Trabecular separation \\
\hline
\end{tabular}




$\begin{array}{ll}\text { TMD } & \text { Tissue mineral density } \\ \text { TNF-a } & \text { Tumor necrosis factor alpha } \\ \text { TRIC } & \text { M. triceps brachii } \\ \text { Tt.Ar } & \text { Total cross-sectional area } \\ \text { Tukey's HSD } & \text { Tukey's honestly significant difference } \\ \text { Wnt } & \text { Wingless-related integration site } \\ \mu \mathrm{CT} & \text { Micro-computed tomography }\end{array}$

\section{Introduction}

Childhood and adolescence are critical periods for the accrual of peak bone mass and structure, defined as the maximal values of skeletal traits present at the end of skeletal maturation [1-3]. Twin and family studies suggest that $60-80 \%$ of peak bone mass variability is attributable to genetic factors, whilst up to $40 \%$ of the remaining variability can be influenced by modifiable factors such as lifestyle and body composition [1,3]. Given that peak bone characteristics may have lifelong influences on bone properties and affect osteoporotic fracture risk later in life [2, 3], a thorough understanding of their determinants is required for the development of novel strategies to combat osteoporosis and prevent fragility fractures.

Among other modifiable factors, the relationship between body composition (muscle and fat mass) and bone during growth in humans has gained considerable interest $[1,4]$. Several pediatric studies suggest that muscle mass and bone mass are closely linked during development [4-7]. Less clear is, however, whether muscle development is driving skeletal development (mechanostat theory) and therefore, whether the attainment of peak muscle mass precedes the acquisition of peak bone mass [8-10]. Studies on the relationship between fat and bone parameters in children, adolescents and young adults have revealed positive, negative or no associations $[4,11,12]$; these discrepancies may reflect methodological differences and/or perplexing bone-fat interactions. Despite the growing evidence, pediatric studies in this area are challenged by uncontrolled genetic and environmental heterogeneity, undesirable radiation exposure during longitudinal bone assessments and bone measurements restricted to certain anatomical sites (e.g., assessment of the distal radius and tibia using high-resolution peripheral quantitative computed tomography or HR-pQCT) [13].

Conversely, animal models provide unique opportunities to study aspects of skeletal health and disease. In particular, inbred mouse strains have a homogeneous genetic background (similar to identical twins) and exhibit various bone phenotypes that can be studied under stringent environmental control. Importantly, bone mass and biomechanical properties in inbred mice appear to be strain dependent [14-21]. For instance, Beamer et al. demonstrated large variations in bone mineral content (BMC) and density (BMD) among
11 inbred strains of mice [14]. Profound strain differences in BMD were found between the $\mathrm{C} 57 \mathrm{BL} / 6 \mathrm{~J}$ and $\mathrm{C} 3 \mathrm{H} / \mathrm{HeJ}$ mice, which are extensively used in skeletal research and considered low and high bone mass strains, respectively. In contrast, normal skeletal phenotypes have been poorly characterized in young DBA/2JRj mice and rarely compared to those of other mouse strains [14, 16, 17]. Strain differences have also been reported in muscle [22, 23] and fat mass [24, 25], whereas investigations that have concomitantly explored bone, muscle and fat are scarce [26].

There are surprisingly limited data on normal patterns of development, especially around skeletal maturity. Significant controversies have been reported regarding the attainment of peak bone properties, even within a given mouse strain, and most available reports have focused on C57BL/6J mice [26-29]. Thus, this period requires further investigation in C57BL/6J mice, but also in other commonly used strains.

As such, we explored age-related changes and strain differences in bone microstructure, body composition and selected biomarkers during development among 3 commonly used male and female inbred mouse strains, namely C57BL/6J, DBA/2JRj and C3H mice, and in this study we report the results for the male animals. Male mice remain understudied compared to female mice [14, 17, 19-21, 30], despite the fact that optimization of skeletal acquisition is crucial for both sexes and skeletal diseases affect both women and men [1-3].

\section{Materials and Methods}

\section{Animals}

Male C57BL/6J (Abteilung für Labortierkunde und Genetik, Himberg, Austria), DBA/2JRj (Janvier Labs, Le Genest-StIsle, France) and C3H/J (Charles River, Sulzfeld, Germany) mice were maintained in our laboratory animal care facility and sacrificed at 8,16 and 24 weeks of age ( $n=6 /$ group). All mice were housed in groups of 2-6 mice/cage and kept under standard conditions on a 12:12 h light/dark cycle. Water and a diet of standard laboratory chow (LASQCdiet $®$ Rod16, Auto; LASvendi GmbH, Soest, Germany) were available ad libitum. All procedures were conducted in accordance with institutional and national guidelines. According to the Austrian animal experimentation law, permission from the Health ministry is not required for this project, since the harvesting of tissues or organs is not regarded as an animal experiment.

\section{Tissue Collection}

All mice were euthanized by carbon dioxide asphyxiation and weighed using an analytical balance. The wet weight 
of several muscles [M. triceps brachii (TRIC), M. quadriceps femoris (QUAD), M. tibialis anterior (TA), M. extensor digitorum longus (EDL), M. gastrocnemius (GAS) and $\mathrm{M}$. soleus (SOL)] was measured using an analytical balance (Sartorius, Göttingen, Germany) at the age of 8, 16 and 24 weeks of age. Retroperitoneal, epididymal, inguinal and mesenteric fat depots were dissected, and their wet mass was weighed at the same time points. The femur and the tibia were defleshed, weighted, preserved in $4 \%$ formaldehyde for $24 \mathrm{~h}$ and stored in $70 \%$ ethanol until microstructural analysis. The lumbar spine was removed and preserved using the same procedures.

\section{Bone Microstructure by Micro-Computed Tomography $(\mu \mathrm{CT})$}

Ex vivo assessments of cortical and trabecular microstructure were performed using $\mu \mathrm{CT}$ (MicroCT 35, Scanco, Switzerland). The X-ray tube was operated at $70 \mathrm{kV}$ with an intensity of $114 \mu \mathrm{A}$, and an exposure time of $800 \mathrm{~ms}$, resulting in a resolution of $10 \mu \mathrm{m} /$ pixel. Cortical structure was determined at the midshaft of the femur and the tibia over a length of $5 \%$ proximal and $5 \%$ distal from the middle of the bone. To determine tissue mineral density of the cortex (Ct.TMD), we used standard Scanco evaluation scripts with the following parameters: (i) Gaussian image noise filter: sigma $=0.8$ and support $=1$, and (ii) a global threshold $>260 \mathrm{mg} \mathrm{HA} / \mathrm{cm}^{3}$. Trabecular microstructure was assessed at the distal femur, proximal tibia and lumbar spine (L4). In the distal femur, trabecular structure was scanned proximal from the epiphysis over a length of $10 \%$ of the total femur. Trabecular morphology was also assessed in the proximal tibia starting at the distal end of the growth plate and extending to a $10 \%$ at distal length of the whole tibia length. Reporting of cortical and trabecular microstructure outcomes were performed according to the American Society for Bone and Mineral Research (ASBMR) guidelines [31]. The cortical parameters assessed were average cortical thickness (Ct.Th), total cross-sectional area (Tt.Ar), cortical bone area (Ct.Ar), cortical bone area fraction (Ct.Ar/Tt.Ar) and Ct.TMD. The trabecular microstructural parameters assessed were trabecular bone volume/total volume (Tb.BV/ $\mathrm{TV}$ ), number (Tb.N), thickness (Tb.Th), trabecular separation (Tb.Sp), connectivity density (Conn.D), trabecular mineral density (Tb.TMD) and structure model index (SMI).

\section{Blood Collection and Biochemical Analysis}

Blood samples were obtained immediately after carbon dioxide asphyxiation. Animals were not fasted prior to blood collection. After centrifugation, serum was isolated and stored at $-80^{\circ} \mathrm{C}$ until further analysis for myostatin and periostin levels. Both markers are emerging candidates of muscle/bone crosstalk [32-36], nevertheless, it remains largely unexplored whether/how periostin and myostatin levels change during the period around peak attainment of musculoskeletal traits. Serum myostatin (R\&D Systems, Abingdon, United Kingdom) and periostin (Biomedica Medizinprodukte $\mathrm{GmbH}$, Vienna, Austria) levels were measured by enzyme-linked immunosorbent assay (ELISA) according to manufacturers' instructions. Myostatin interassay $\mathrm{CV}$ was $\leq 6 \%$ between 31.3 and $2000 \mathrm{pg} / \mathrm{mL}$ and the sensitivity was $5.32 \mathrm{pg} / \mathrm{mL}$. The inter-assay CV for periostin was $\leq 6 \%$ between 0 and $16 \mathrm{nmol} / \mathrm{L}$ and the detection limit was $0.003 \mathrm{nmol} / \mathrm{L}$.

\section{Statistical Analysis}

All variables were checked for normality using the Shapiro-Wilk test. Values are presented as mean and standard error (SE). For normally distributed data, two-way analysis of variance (ANOVA) was used to assess the main effects of strain and age, and their interaction on skeletal and body composition characteristics and biochemical markers. Tukey's (honestly significant difference) HSD post hoc test was used to locate significant main effects. In case of a significant interaction effect, one-way ANOVA was performed to evaluate age-related changes within each strain and strain differences at each time point. For non-normally distributed data, Kruskal-Wallis and Mann-Whitney tests were used. A maximal value (median) in skeletal, body composition, and biochemical parameters was statistically identified, if there was a significant effect of age within each strain using a one-way ANOVA or Kruskal-Wallis test. To estimate effect sizes, Cohen's d was determined by calculating the mean difference between your two groups, and then dividing the result by the pooled standard deviation. Cohen's $d=0.2$ is considered a 'small' effect size, 0.5 represents a 'medium' effect size and $\geq 0.8$ a 'large' effect size (Supplementary Tables 1 and 2). All analyses were performed using the statistical package for social sciences (SPSS) version 24.0 (Chicago, IL, USA) with statistical significance set at $p \leq 0.05$.

\section{Results}

\section{Body Weight}

In all mouse strains, body weight increased over the time frame of the study $(8<24$ weeks of age) (Fig. 1, Supplementary Table 3 ). At 8 weeks of age, $\mathrm{C} 3 \mathrm{H} / \mathrm{J}$ mice had higher body weights than $\mathrm{C} 57 \mathrm{BL} / 6 \mathrm{~J}$, and at 16 weeks, $\mathrm{C} 3 \mathrm{H} / \mathrm{J}$ mice were heavier than both $\mathrm{C} 57 \mathrm{BL} / 6 \mathrm{~J}$ and DBA/2JRj mice. At 24 weeks, however, there were no strain differences. This is because $\mathrm{C} 57 \mathrm{BL} / 6 \mathrm{~J}$ mice experienced rapid increases in body weight after week $16(p=0.008), \mathrm{DBA} / 2 \mathrm{JRj}$ mice 
Table 1 Timing of maximal/ minimal values of cortical bone characteristics within the timeframe of the study (8-24 weeks of age)

\begin{tabular}{|c|c|c|c|c|c|c|c|}
\hline & & Femur & & & Tibia & & \\
\hline & & 8 weeks & 16 weeks & 24 weeks & 8 weeks & 16 weeks & 24 weeks \\
\hline Maximal Ct.Th & C57BL/6J & & & $x$ & & & $x$ \\
\hline & $\mathrm{DBA} / 2 \mathrm{JRj}$ & & & $x$ & & & $x$ \\
\hline & $\mathrm{C} 3 \mathrm{H} / \mathrm{J}$ & & & $x$ & & & $x$ \\
\hline Maximal Ct.TMD & C57BL/6J & & & $x$ & & & $x$ \\
\hline & DBA/2JRj & & & $x$ & & & $x$ \\
\hline & $\mathrm{C} 3 \mathrm{H} / \mathrm{J}$ & & & $x$ & & & $x$ \\
\hline Maximal Tt.Ar & C57BL/6J & & & $x$ & & & $x$ \\
\hline & $\mathrm{DBA} / 2 \mathrm{JRj}$ & & & $x$ & & $x$ & \\
\hline & $\mathrm{C} 3 \mathrm{H} / \mathrm{J}$ & & $x$ & & & & $x$ \\
\hline Maximal Ct.Ar & C57BL/6J & & & $x$ & & & $x$ \\
\hline & $\mathrm{DBA} / 2 \mathrm{JRj}$ & & & $x$ & & $x$ & \\
\hline & $\mathrm{C} 3 \mathrm{H} / \mathrm{J}$ & & $x$ & & & & $x$ \\
\hline Maximal Ct.Ar/Tt.Ar & C57BL/6J & & & $x$ & & & $x$ \\
\hline & $\mathrm{DBA} / 2 \mathrm{JRj}$ & & & $x$ & & & $x$ \\
\hline & $\mathrm{C} 3 \mathrm{H} / \mathrm{J}$ & & $x$ & & & & $x$ \\
\hline
\end{tabular}

Cortical structure was determined at the midshaft of the femur and the tibia. A maximal/minimal value (median) was statistically identified, if there was a significant effect of age within each strain using a oneway ANOVA or Kruskal-Wallis test. Crosses denote that maximal/minimal value (median) was achieved at 8,16 or 24 weeks of age; absence of crosses indicate that we did not statistically identify a maximal/minimal value within the timeframe of the study

Ct.Th average cortical thickness, Ct.Ar cortical bone area, Ct.TMD cortical tissue mineral density, $T t . A r$ total cross-sectional area, Ct.Ar/Tt.Ar cortical bone area fraction (one column)

Table 2 Timing of maximal/minimal values of trabecular bone characteristics within the timeframe of the study (8-24 weeks of age)

\begin{tabular}{|c|c|c|c|c|c|c|c|c|c|c|}
\hline & & \multicolumn{3}{|l|}{ Femur } & \multicolumn{3}{|l|}{ Tibia } & \multicolumn{3}{|c|}{ Lumbar spine } \\
\hline & & 8 weeks & 16 weeks & 24 weeks & 8 weeks & 16 weeks & 24 weeks & 8 weeks & 16 weeks & 24 weeks \\
\hline \multirow[t]{3}{*}{ Maximal Tb.BV/TV } & $\mathrm{C} 57 \mathrm{BL} / 6 \mathrm{~J}$ & & & & & & $x$ & & & $x$ \\
\hline & $\mathrm{DBA} / 2 \mathrm{JRj}$ & $x$ & & & & $x$ & & & $x$ & \\
\hline & $\mathrm{C} 3 \mathrm{H} / \mathrm{J}$ & $x$ & & & & & & & $x$ & \\
\hline \multirow[t]{3}{*}{ Maximal Tb.N } & C57BL/6J & & & & & & & $x$ & & \\
\hline & $\mathrm{DBA} / 2 \mathrm{JRj}$ & $x$ & & & $x$ & & & $x$ & & \\
\hline & $\mathrm{C} 3 \mathrm{H} / \mathrm{J}$ & $x$ & & & & & & & $x$ & \\
\hline \multirow[t]{3}{*}{ Maximal Tb.Th } & C57BL/6J & & & $x$ & & & $x$ & & & $x$ \\
\hline & $\mathrm{DBA} / 2 \mathrm{JRj}$ & & & & & & $x$ & & $x$ & \\
\hline & $\mathrm{C} 3 \mathrm{H} / \mathrm{J}$ & & & & & & $x$ & & & \\
\hline \multirow{3}{*}{$\begin{array}{l}\text { Minimal } \\
\text { Tb.Sp }\end{array}$} & C57BL/6J & & & & & & & & & \\
\hline & $\mathrm{DBA} / 2 \mathrm{JRj}$ & $x$ & & & $x$ & & & $x$ & & \\
\hline & $\mathrm{C} 3 \mathrm{H} / \mathrm{J}$ & $x$ & & & & & & & $x$ & \\
\hline
\end{tabular}

Trabecular bone microstructure was assessed at the distal femur, proximal tibia and forth vertebral body (L4). A peak value (median) was statistically identified, if there was a significant effect of age within each strain using a one-way ANOVA or Kruskal-Walis test. Crosses denote that maximal/minimal value (median) was achieved at 8,16 or 24 weeks of age; absence of crosses indicate that we did not statistically identify a maximal/minimal value

$T b . B V / T V$ trabecular bone volume/tissue volume, $T b . N$ trabecular number, $T b . T h$ trabecular thickness, $T b . S p$ trabecular separation (two columns)

also experienced body weight increases, which, however, did not reach statistical significance $(p=0.071)$, whereas, in $\mathrm{C} 3 \mathrm{H} / \mathrm{J}$ mice, body weight stabilized between weeks 16 and $24(p=1.0)$.

\section{Age-Related Changes in Cortical Bone Microstructure}

In C57BL/6J and DBA/2JRj, Ct.Th and Ct.TMD at the femur and the tibia increased between 8 and 24 weeks, and 
Fig. 1 Weight (A), muscle sum (B) and fat sum (C) in C57BL/6J (white columns), DBA/2JRj (light grey columns) and $\mathrm{C} 3 \mathrm{H} / \mathrm{J}$ (dark grey columns) at 8,16 , and 24 weeks of age. The boxes represent medians, as well as upper and lower quartiles and the whiskers indicate the minimum and maximum values. Muscle sum was calculated as the sum of the mass of six individual muscles (M. triceps brachii, M. quadriceps femoris, M. tibialis anterior, M. extensor digitorum longus, M. gastrocnemius and M. soleus) dissected from the left arm and leg of each animal. Fat sum was calculated as the sum of the mass of 4 fat depots (retroperitoneal, epididymal, inguinal and mesenteric). Strain difference at each time point are indicated by arrows. Time differences within each stain are denoted with letters: a, indicates a difference between 8 and 16 weeks of age within the same strain; $b$, indicates a difference between 8 and 24 weeks of age within the same strain; c, indicates a difference between 16 and 24 weeks of age within the same strain (one column)

reached maximal values at 24 weeks (Fig. 2, Table 1, Supplementary Table 4). The highest Ct.Ar/Tt.Ar occurred at 24 weeks and largely reflected the simultaneous highest values seen in Ct.Ar and Tt.Ar.

Similar cortical bone growth patterns were seen in $\mathrm{C} 3 \mathrm{H} / \mathrm{J}$ mice at the tibia. At the femur, Ct.Th and Ct. TMD were greatest at 24 weeks of age (Fig. 2, Table 1, Supplementary Table 4), however, Ct.Ar, Tt.Ar and Ct.Ar/Tt.Ar were highest at 16 weeks. Although there were no significant changes in Ct.Ar and Tt.Ar between weeks 16 and 24, Ct.Ar/Tt.Ar markedly decreased within this time frame, suggesting some age-related thinning of the cortex.

\section{Strain-Related Differences in Cortical Bone Microstructure}

At both the femur and the tibia, and at all time points, $\mathrm{C} 3 \mathrm{H} / \mathrm{J}$ mice had the thickest cortices followed by DBA/2JRj and C57BL/6J mice (Fig. 2, Supplementary Table 4). Overall, C57BL/6J mice had smaller Ct.TMD and Ct.Ar/Tt.Ar than $\mathrm{DBA} / 2 \mathrm{JRj}$ and $\mathrm{C} 3 \mathrm{H} / \mathrm{J}$ mice. Small age-related differences were found in Ct.Ar/Tt.Ar between DBA/2JRj and C3H/J mice at the tibia and the femur.

\section{Age-Related Changes in Trabecular Bone Microstructure}

In C57BL/6J mice, Tb.BV/TV at the tibia and the lumbar spine increased between 8 and 24 weeks of age (Fig. 3, Table 2, Supplementary Table 5). The highest tibia and lumbar Tb.BV/TV were accompanied by maximal $\mathrm{Tb}$. Th values at 24 weeks, whereas the effects of age on Tb.N and $\mathrm{Tb} . \mathrm{Sp}$ were less consistent. The age-related effects on femoral Tb.BV/TV, Tb.N, and Tb.Sp were weak and we were not able to statistically identify highest values. Taken together, these results suggest that maximal trabecular bone properties
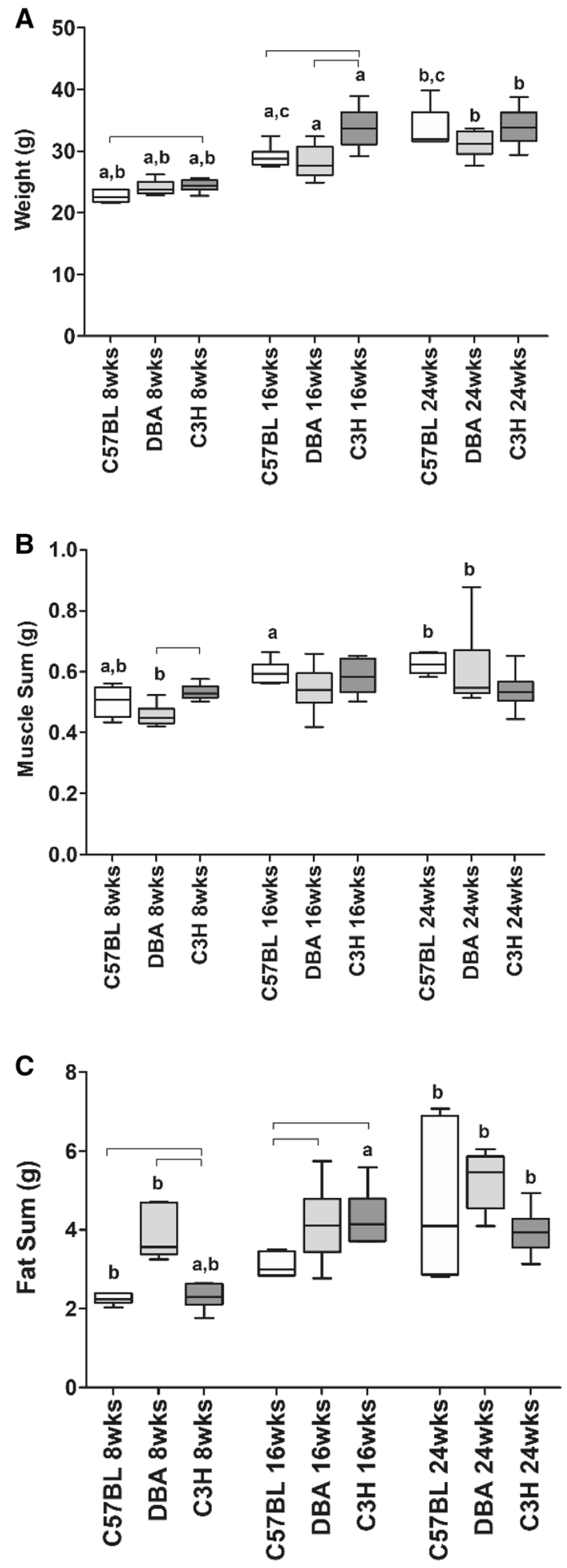

in $\mathrm{C} 57 \mathrm{BL} / 6 \mathrm{~J}$ mice occurred at 24 weeks or beyond the follow-up period of this study.

In contrast, DBA/2JRj mice experienced the highest femoral Tb.BV/TV early at 8 weeks, which appeared to be the result of greatest Tb.N and lowest Tb.Sp at this time point (Fig. 3, Table 2, Supplementary Table 5). 
Fig. 2 Cortical thickness (Ct. $\mathrm{Th}$ ) and tissue mineral density (Ct.TMD) at the femur (A, B) and the tibia $(\mathbf{C}, \mathbf{D})$ in C57BL/6J (white boxes), DBA/2JRj (light grey boxes) and $\mathrm{C} 3 \mathrm{H} / \mathrm{J}$ (dark grey boxes) at 8,16 , and 24 weeks of age. The boxes represent medians, as well as upper and lower quartiles and the whiskers indicate the minimum and maximum values. Strain difference at each time point are indicated by arrows. Time differences within each stain are denoted with letters: a, indicates a difference between 8 and 16 weeks of age within the same strain; $b$, indicates a difference between 8 and 24 weeks of age within the same strain; c, indicates a difference between 16 and 24 weeks of age within the same strain (2 columns)
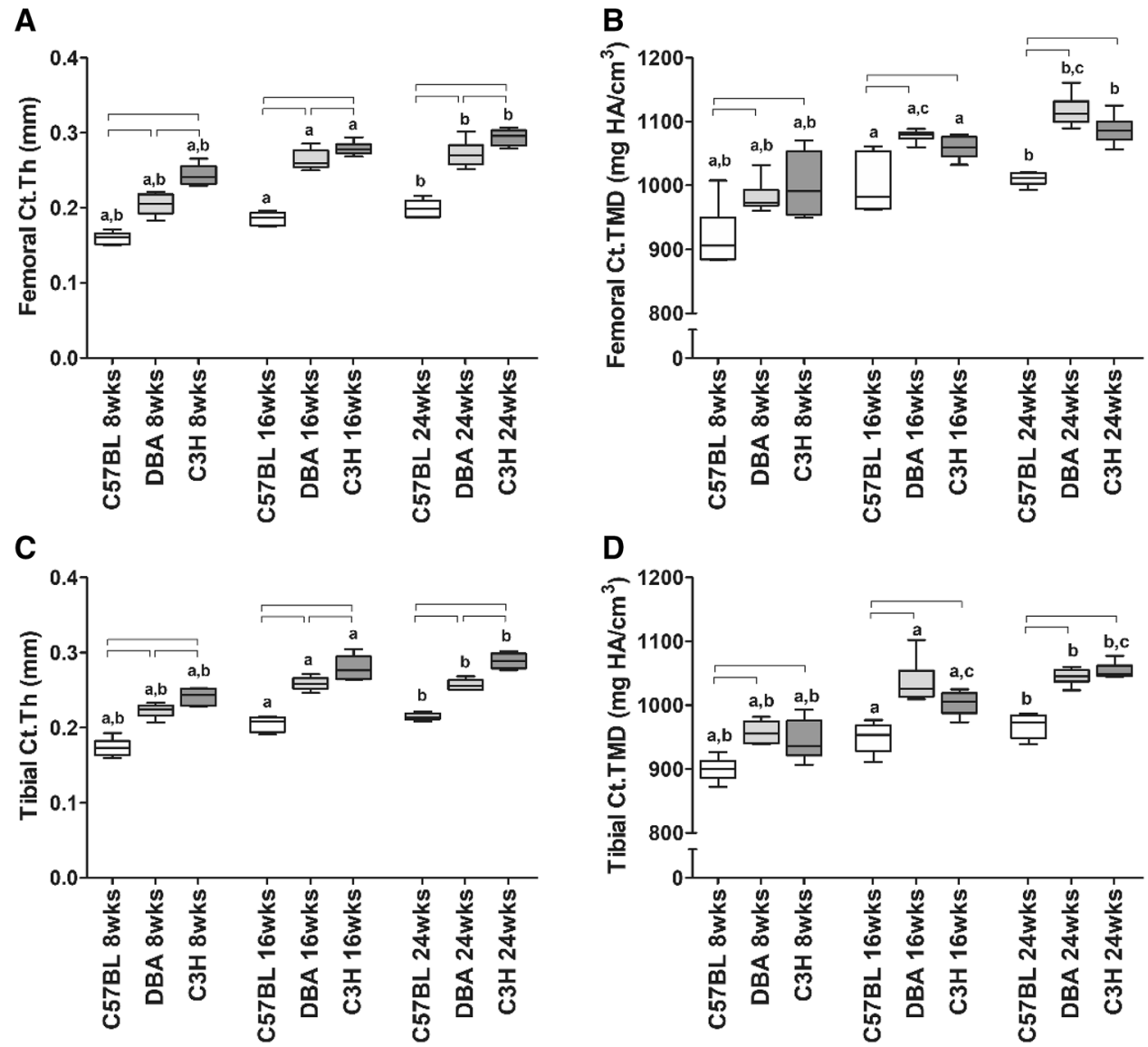

Similar developmental patterns (highest values achieved at 8-16 weeks of age) were observed trabecular bone parameters at the tibia and lumbar spine.

Age-related changes in trabecular bone architecture in C3H/J mice were highly site specific (Fig. 3, Table 2, Supplementary Table 5). In $\mathrm{C} 3 \mathrm{H} / \mathrm{J}$ mice, the highest femoral Tb.BV/TV values were observed at 8 weeks; this peak paralleled the greatest Tb.N and lowest Tb.Sp. Tb.BV/TV at L4 reached a maximum at 16 weeks, similarly reflecting the highest Tb.N and the lowest Tb.Sp. Finally, tibial Tb.BV/ $\mathrm{TV}$ and Tb.N increased and Tb.Sp decreased progressively over time. These changes, however, did not reach statistical significance, preventing us from statistically identifying maximal/minimal values for these parameters.

\section{Strain-Related Differences in Trabecular Bone Microstructure}

Between strain analyses suggest that C57BL/6J mice have higher Tb.BV/TV and Tb.N, and lower Tb.Sp than $\mathrm{DBA} / 2 \mathrm{JRj}$ and $\mathrm{C} 3 \mathrm{H} / \mathrm{J}$ mice at least at 24 weeks of age at all skeletal sites (Fig. 3, Supplementary Table 3). Thus, the less favorable cortical bone characteristics in C57BL/6J mice appear to be counterbalanced by gains and rearrangement of the trabecular compartment in the longer-term. DBA/2JRj mice had consistently thinner trabeculae than $\mathrm{C} 57 \mathrm{BL} / 6 \mathrm{~J}$ and $\mathrm{C} 3 \mathrm{H} / \mathrm{J}$ mice at all skeletal sites at least at 24 weeks of age. Less pronounced strain differences were seen in other trabecular microstructure parameters among DBA/2JRj and $\mathrm{C} 3 \mathrm{H} / \mathrm{J}$ mice depending on skeletal site. For example, at the femur, DBA/2JRj mice had lower Tb.N and higher Tb.Sp than $\mathrm{C} 3 \mathrm{H} / \mathrm{J}$ mice at 24 weeks, whereas at the lumbar spine, these parameters were higher (Tb.N)/lower (Tb.Sp) in $\mathrm{DBA} / 2 \mathrm{JRj}$ mice compared to $\mathrm{C} 3 \mathrm{H} / \mathrm{J}$ mice.

\section{Age- and Strain-Related Differences in Body Composition}

C57BL/6J and DBA/2JRj mice experienced significant increases in their muscle mass (the sum of the mass of six individual muscles: M. triceps brachii, M. quadriceps femoris, M. tibialis anterior, M. extensor digitorum longus, M. gastrocnemius and M. soleus) by 24 weeks of age (Fig. 1). Age-related differences in the mass of individual muscle masses and their sum expressed in absolute terms and relative to body weight are presented in Supplementary Tables 1 and 4. In $\mathrm{C} 3 \mathrm{H} / \mathrm{J}$ mice, mass of individual muscles and their sum remained largely unchanged throughout this study. Overall, DBA/2JRj mice had lower muscle mass (sum or individual muscles) than $\mathrm{C} 3 \mathrm{H} / \mathrm{J}$ and/or $\mathrm{C} 57 \mathrm{BL} / 6 \mathrm{~J}$ mice at 

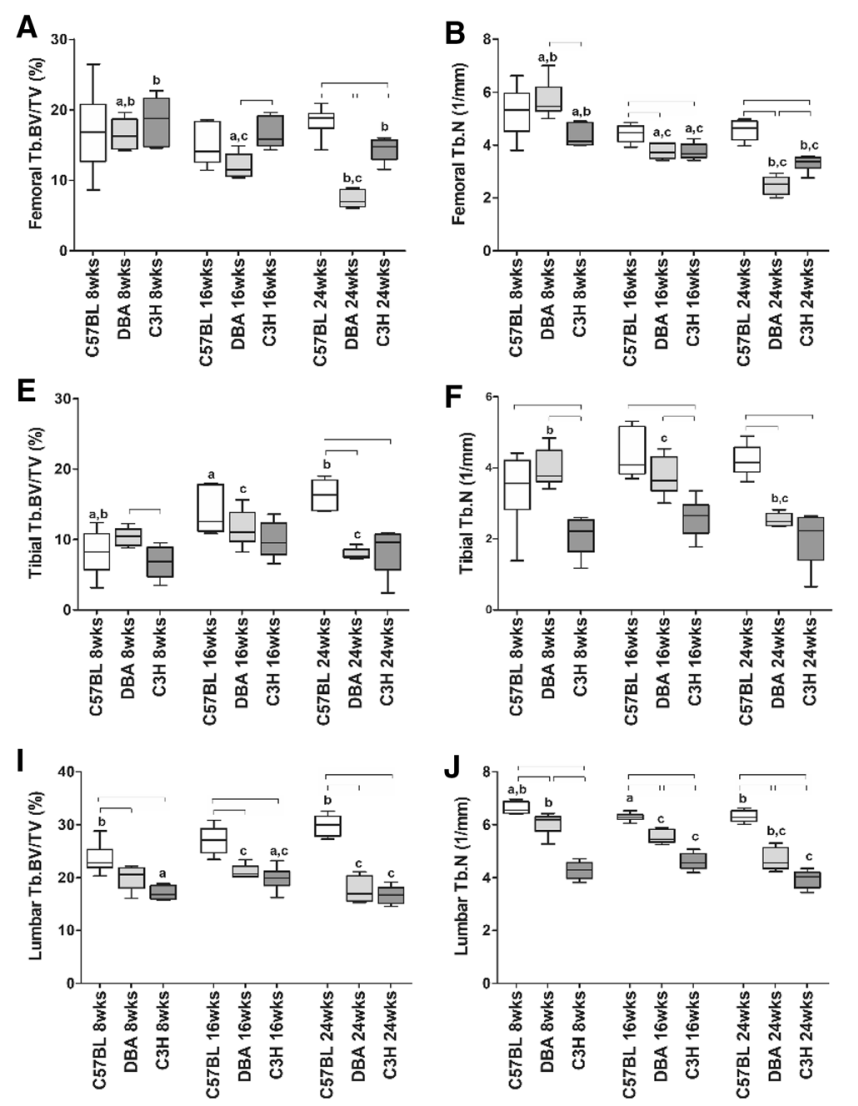

Fig. 3 Trabecular bone microstructural parameters at the femur (AD), tibia (E-H) and lumbar spine (L4) (I-L) in C57BL/6J (white boxes), DBA/2JRj (light grey boxes) and $\mathrm{C} 3 \mathrm{H} / \mathrm{J}$ (dark grey boxes) at 8,16 , and 24 weeks of age. The boxes represent medians, as well as upper and lower quartiles and the whiskers indicate the minimum and maximum values. Strain difference at each time point are indicated by

8 weeks of age. At 16 weeks, there were no strain differences in muscle sum or in the mass of individual muscles. At 24 weeks, C57BL/6J mice had greater site-specific muscle mass (M. gastrocnemius and M. soleus) than both DBA/2JRj and $\mathrm{C} 3 \mathrm{H} / \mathrm{J}$ mice, but the sum of the 6 individual muscle masses did not differ between strains.

In C57BL/6J and DBA/2JRj mice, the mass of selected fat depots (retroperitoneal, epididymal, inguinal and mesenteric), as well as their sum, increased progressively over time (greatest values observed at 24 weeks) (Fig. 1, Supplementary Table 1). In $\mathrm{C} 3 \mathrm{H} / \mathrm{J}$ mice, highest values of fat depots masses were largely achieved by 16 weeks of age and maintained at 24 weeks. Overall, early in the study (8 weeks), DBA/2JRj mice had heavier fat depots than C57BL/6J and $\mathrm{C} 3 \mathrm{H} / \mathrm{J}$ mice, however, no significant strain differences were seen in fat quantity and distribution at 24 weeks of age.

In agreement with recent findings [37], correlation analyses for strain (data pooled for time) revealed that weight was positively correlated with cortical parameters and Tb.Th in all strains (Supplementary Table 5). Positive correlations
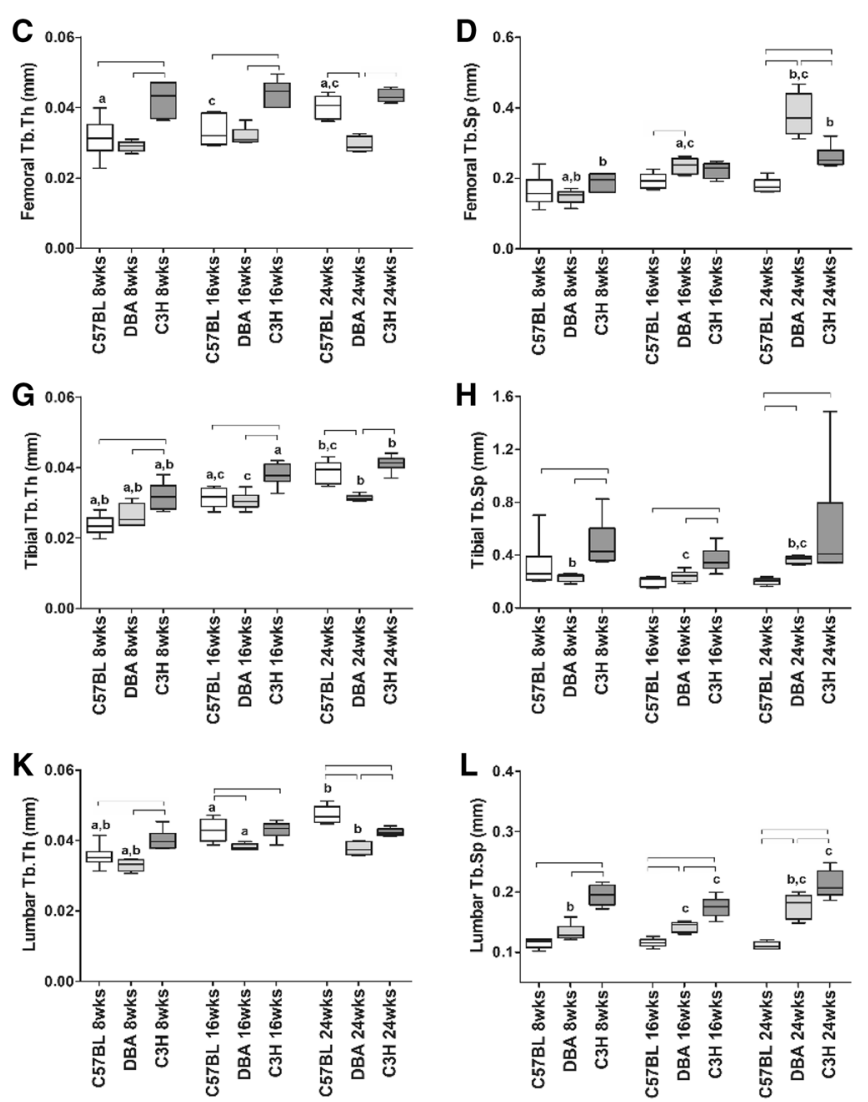

arrows. Strain difference at each time point are indicated by arrows. Time differences within each stain are denoted with letter: a, indicates a difference between 8 and 16 weeks of age within the same strain; $\mathrm{b}$, indicates a difference between 8 and 24 weeks of age within the same strain; c, indicates a difference between 16 and 24 weeks of age within the same strain. (two columns)

were observed between Tb.BV/TV in C57BL/6J and C3H/J, but negative correlations between these variables were seen in DBA/2JRj mice. Muscle sum was positively correlated with cortical parameters in C57BL/6J and DBA/2JRj mice. Positive correlations were seen between muscle sum and trabecular parameters in C57BL/6J (both sites) and $\mathrm{C} 3 \mathrm{H} / \mathrm{J}$ mice (at L4 only), whereas muscle sum and trabecular bone parameters were negatively in DBA/2JRj mice. Fat mass was positively associated with cortical parameters and trabecular parameters in $\mathrm{C} 57 \mathrm{BL} / 6 \mathrm{~J}$ and $\mathrm{C} 3 \mathrm{H} / \mathrm{J}$ mice, while negative correlations were seen between fat mass, cortical and trabecular parameters in DBA/2JRj mice.

\section{Age- and Strain-Related Differences in Biochemical Markers}

In C57BL/6J and DBA/2JRj mice, myostatin levels did not change over time (Fig. 4). $\mathrm{C} 3 \mathrm{H} / \mathrm{J}$ mice had highest myostatin levels at 8 weeks, after this point they experienced decreases by 24 weeks Between strain comparisons revealed that at 


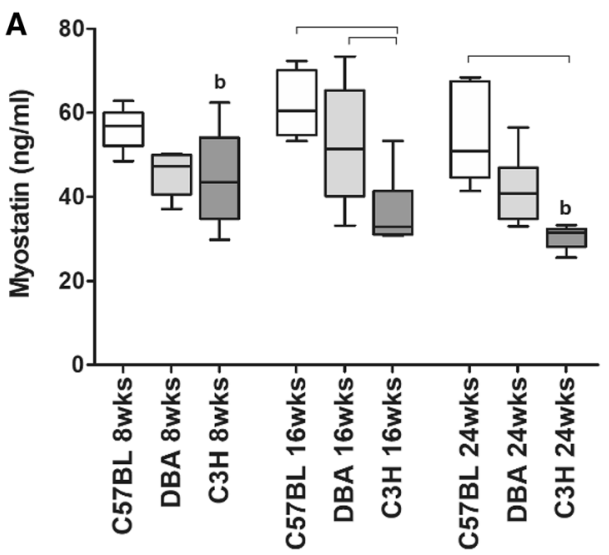

Fig. 4 Myostatin (A) and periostin (B) levels in C57BL/6J (white boxes), DBA/2JRj (light grey boxes) and $\mathrm{C} 3 \mathrm{H} / \mathrm{J}$ (dark grey boxes) at 8,16 , and 24 weeks of age. The boxes represent medians, as well as upper and lower quartiles and the whiskers indicate the minimum and maximum values. Strain difference at each time point are indicated by

16 and 24 weeks of age, $\mathrm{C} 3 \mathrm{H} / \mathrm{J}$ mice had lower myostatin levels than C57BL/6J and, to a less extent than DBA/2JRj mice (at 24 weeks, $p=0.079$ ). At 24 weeks, there was also a weak strain effect indicating that DBA/2JRj mice had lower myostatin levels than C57BL/6J $(p=0.053)$. Data pooled for age confirmed these strain differences; $\mathrm{C} 3 \mathrm{H} / \mathrm{J}$ mice had the lowest myostatin levels, followed by DBA/2JRj and C57BL/6J mice.

In all mouse strains, periostin levels were greatest at 8 weeks and decreases occurred by 24 weeks of age (Fig. 4). Strain differences were seen only at 16 weeks, when $\mathrm{DBA} / 2 \mathrm{JRj}$ mice had greater periostin levels than $\mathrm{C} 3 \mathrm{H} / \mathrm{J}$ mice and, to a less extent, than C57BL/6J $(p=0.065)$.

\section{Discussion}

This study presents baseline data that describe normal skeletal growth patterns and changes in body composition with age in 3 inbred mouse strains. We confirm and extend previous observations regarding strain specificity in bone microstructure. We also provide new evidence on inter- and intrastrain variability in the patterns (i.e., timing, magnitude, site) of cortical and trabecular bone development. Finally, this work advances our understanding regarding the relationships of skeletal microstructure, body composition, and relevant biomarkers (periostin and myostatin) and set the basis for delineating the contributions of these relationship in osteoporosis and sarcopenia.

We showed clear strain-specific phenotypic differences in cortical and trabecular bone microstructure. $\mathrm{C} 3 \mathrm{H} / \mathrm{J}$ mice had the thickest cortices at all skeletal sites followed by DBA/2JRj and C57BL/6J mice. Conversely, overall,

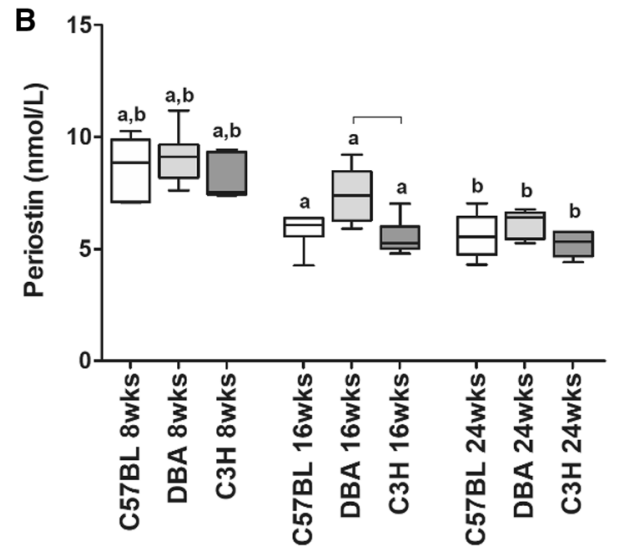

arrows. Time differences within each stain are denoted with letters: a, indicates a difference between 8 and 16 weeks of age within the same strain; b, indicates a difference between 8 and 24 weeks of age within the same strain; c, indicates a difference between 16 and 24 weeks of age within the same strain. (two columns)

C57BL/6J mice had smaller cortical bone area fraction and tissue mineral density than DBA/2JRj and $\mathrm{C} 3 \mathrm{H} / \mathrm{J}$ mice, whilst small differences were found between DBA/2JRj and $\mathrm{C} 3 \mathrm{H} / \mathrm{J}$ mice. These results confirm previous studies that compared C3H/J and C57BL/6J female [14, 17, 19-21, 38] and male mice $[15,16,18]$ and further indicate that male DBA/2JRj mice display intermediate values in cortical bone parameters.

The inferior cortical bone characteristics in C57BL/6 J mice were counterbalanced by longer-term gains in the trabecular compartment. This is supported by the higher trabecular BV/TV and trabecular number, and lower trabecular separation seen in C57BL/6J mice compared to DBA/2JRj and $\mathrm{C} 3 \mathrm{H} / \mathrm{J}$ mice at least at 24 weeks of age. Our data are consistent with some [18,21], but not all previous comparisons between $\mathrm{C} 3 \mathrm{H} / \mathrm{J}$ and C57BL/6J mice [14]. These discrepancies may be partially explained by differences in the methodologies used to assess bone structure ( $\mu \mathrm{CT}$ vs. pQCT) and ages between ours and their experimental animals. The most pronounced characteristic of trabecular microstructure in DBA/2JRj mice was their consistently thinner trabeculae (vs. C57Bl/6J and $\mathrm{C} 3 \mathrm{H} / \mathrm{J}$ mice). Collectively, our work clarifies that strain differences are compartment specific and indicates that labelling a strain according to a sole complex trait such as bone mass may mask pronounced differences in cortical and trabecular bone properties.

We found that cortical and trabecular compartments may be differentially affected by age and that growth patterns differ among strains. In C57BL/6J mice, cortical and trabecular bone development peaked at the same timeframe (24 weeks of age). The same developmental pattern was seen for both cortical sites assessed. The vertebra and the proximal tibia shared similarities in trabecular bone development; 
however, in the distal femur we did not statistically identify age-related effects. The main mechanism of trabecular microstructure augmentation at the lumbar spine in C57BL/6J mice was thickening of the existing trabeculae, whereas trabecular number declined after 8 weeks of age. This decrease in trabecular number may be associated with altered remodeling processes, which aim to reorganize trabecular bone in response to prevalent loading conditions. In line with previous observations [29], the continuous increase in mean trabecular thickness may reflect the increased stress imposed to a reduced number of trabeculae. An alternative explanation why mean trabecular thickness increases, is that, as thinner trabeculae are resorbed, there is an increase in the average thickness of residual trabeculae. Previous observations have also shown that $\mathrm{C} 57 \mathrm{Bl} / 6 \mathrm{~J}$ mice achieve peak structural, material and mechanical bone properties after 20 weeks of age [20, 28, 39]. In contrast, Glatt et al. studied age-related changes in bone morphology in male C57BL/6J mice and showed earlier increases (peak reached by 8 weeks) and subsequent maintenance (up to 24 weeks) in lumbar BV/TV, which were accompanied by elevations in trabecular number by 8 weeks and increases in trabecular thickness up to 16 weeks of age [29]. Small differences in growth patterns were seen in the distal femur and proximal tibia [29]. These discrepant findings can be in part attributed to differences in sampling frequency, intergroup variability and site evaluation (L4 vs. L5).

Normal growth patterns in $\mathrm{DBA} / 2 \mathrm{JRj}$ and $\mathrm{C} 3 \mathrm{H} / \mathrm{J}$ mice remain poorly investigated. In DBA/2JRj mice, cortical bone maturity was reached at 24 weeks of age. Highest values of trabecular bone properties were, however, achieved earlier, between 8 and 16 weeks of age, depending on anatomical site, and these gains were associated with a higher number of trabeculae and favorable organization. In $\mathrm{C} 3 \mathrm{H} / \mathrm{J}$ mice, different growth patterns were observed at different anatomical sites. For example, maturity of cortical bone at the tibia was achieved at 24 weeks, whereas we did not statistically detect maximal values for most tibial trabecular parameters. This observation indicates that either there were no overt trabecular bone changes over time or that trabecular characteristics at this site peaked beyond the timeframe of our study. In contrast, at the femur, cortical thickness was greatest at 24 weeks, however, cortical bone area fraction decreased markedly after 16 weeks, suggesting some age-related thinning of the cortex. Skeletal maturity at the femoral trabecular sites was also achieved early, as indicated by peak femoral trabecular BV/TV at 8 weeks; this peak resulted primarily from increases in trabecular number rather than thickening. Trabecular bone properties in the lumbar spine reached maximal levels at 16 weeks and declined after this time point. Previously published data suggest that $\mathrm{C} 3 \mathrm{H} / \mathrm{J}$ mice display maximal skeletal morphological and biomechanical properties before 16 weeks of age [20]. We speculate that differences in load distribution characteristics in the different skeletal sites may contribute to the different patterns of age-related trabecular bone changes in $\mathrm{C} 3 \mathrm{H} / \mathrm{J}$ mice.

In addition to age- and strain- related differences in skeletal morphology, we explored how changes in body composition (muscle, fat) and relevant biochemical markers relate to skeletal characteristics during development. In human studies, there is consensus that lean mass is positively associated with bone parameters [4-7, 12]. Furthermore, some [8, 10], albeit not all [9], studies, have shown that peak muscle mass precedes peak bone mass, further supporting the notion that muscle accrual impacts bone acquisition. These positive association between lean mass and BMD have been largely attributed to the direct mechanical impact (muscle contractions, weight of muscle) of muscle on bone as described in the mechanostat theory [40].

We extend our understanding on the bone-muscle relationship during growth and propose that the relationship may be compartment dependent. We showed that the highest muscle mass and cortical bone properties occurred at 24 weeks of age in $\mathrm{C} 3 \mathrm{H} / \mathrm{J}$ and DBA/2JRj mice, whereas more variable cortical skeletal development patterns were seen in $\mathrm{C} 3 \mathrm{H} / \mathrm{J}$ mice. These results may reflect the observations that muscle mass increased progressively in C57BL/6J and DBA/2JRj mice, whereas it did not change over time in $\mathrm{C} 3 \mathrm{H} / \mathrm{J}$ mice. Due to our sampling frequency, it remains uncertain whether cortical bone acquisition follows peak muscle mass; nevertheless, our findings suggest that maximal values in both tissues may occur at the same timeframe. Our data could also be explained by available reports suggesting that mouse strains respond differently to mechanical stress. Indeed, $\mathrm{C} 3 \mathrm{H}$ mice have been shown to be less sensitive to mechanical loading and unloading conditions than C57BL/6J mice [41, 42]. Alternatively, our finding may reflect collinear growth of muscle and bone tissues, regulated by genetic, endocrine and environmental factors $[2,32,43]$.

Our findings do not support the notion that changes in muscle mass drive adaptations of trabecular bone during growth. For instance, overall, trabecular bone parameters reached maximum at 24 weeks in $\mathrm{C} 57 \mathrm{BL} / 6 \mathrm{~J}$, but at 8-16 weeks for DBA/2JRj mice, despite continuous increases in muscle mass by 24 weeks of age in both strains. These results may indicate that genetics, environmental and intrinsic factors and their complex interactions may override the effects of muscle mass on trabecular bone. It has been proposed that $\mathrm{C} 3 \mathrm{H} / \mathrm{J}$ mice possess sets of genes that lead to enhanced cortical bone properties and impaired trabecular bone $[14,16,21]$. Another possibility is that trabecular bone adaptations are driven by intrinsic bone factors. Indeed, the superior cortical bone structure in $\mathrm{C} 3 \mathrm{H} / \mathrm{J}$ mice is likely to carry a major part of mechanical load, leading to stress protective responses and resorption of trabecular bone [17, 21]. 
In addition to the mechanical interactions between bone and muscle, these tissues are also linked through secreted factors (i.e. myokines, osteokines, systemic hormones) [32, 33]. Myostatin, a potentially negative regulator of muscle growth and regeneration expressed predominantly in skeletal muscle, is a candidate of muscle-bone interactions. Age- and strain-related differences in myostatin levels were not reflected in the rather small muscle mass changes over time in either mouse strain. A potential explanation for these results is that myostatin abundance in serum may not reflect its activity, which is inhibited by several proteins (e.g., follistatin) [44]. Nevertheless, strain differences in myostatin levels might have contributed to the observed skeletal phenotypes during growth. $\mathrm{C} 3 \mathrm{H} / \mathrm{J}$ mice had the lowest myostatin levels and favorable cortical bone parameters, whereas C57BL/6J had the highest myostatin levels and the worst cortical microstructure. These observations are consistent with animal studies showing that myostatin knock out mice have increased periosteal circumference and tissue mineral density [33, 34].

Periostin is expressed in several tissues including bone and skeletal muscle [35]. In bone, periostin is a structural component of bone matrix, but also acts as a signaling molecule, which, through different pathways (i.e., sclerostin/ Wnt-b catenin pathway), enhances osteoblast function, and hence, bone formation [35]. Deletion of the periostin gene in mice results in low bone mass, less favorable cortical bone structure and low bone strength in young adult mice $[45,46]$. Periostin is also expressed by skeletal myofibers and has been shown to contribute to muscle development, regeneration and differentiation [36]. In our work, in all mouse strains, periostin levels were maximal at 8 weeks of age and declined thereafter, a finding consistent with the age-related decreases in periostin reported previously [35]. Theoretically, these results may reflect rapid stimulation of bone formation and/or muscle development at earlier time points. Nevertheless, given that periostin is non-specific to bone or muscle and serum periostin levels are reflective of the metabolism of other tissues as well; future studies are needed to elucidate the contribution of periostin to musculoskeletal phenotypes during development.

The relationship between fat mass and BMD in pediatric and young adult population is controversial, as available studies have demonstrated a positive, negative or no association [4, $6,12]$. It is plausible that these discrepancies somewhat reflect the complex interactions between bone and fat. Although the mechanical contribution of fat mass is limited to its weight, biochemical links between bone and fat are suggested to play a major role in the interplay of these tissues and are mediated by adipokines, osteokines, hormones and inflammatory factors [47]. Low body fat content and adiposity during growth may also impact the timing of maturation by affecting the secretion of molecules that exert positive (IGF-1), dual (leptin) or negative effects (tumor necrosis factor or TNF-a, interleukin 6 or IL-6) on bone $[47,48]$. We speculate that this may be one of the reasons why DBA/2JRj mice and $\mathrm{C} 3 \mathrm{H} / \mathrm{J}$ mice (higher fat mass at early time points) experience earlier maturation than C57BL/6J mice. We also showed that fat mass increased progressively in all strains and paralleled the highest values in cortical thickness, despite variable developmental patterns in trabecular bone parameters. Further studies are needed to disentangle the effects of normal body fat levels on bone, together with the mechanisms that mediate these effects.

\section{Strengths and Limitations}

This study is strengthened by the powerful $\mu \mathrm{CT}$ imaging technique, which is non-destructive, accurate and widely used for the evaluation of three-dimensional bone microstructure [31]. Indeed, $\mu \mathrm{CT}$ measurements are highly correlated with measurements acquired by (static) histomorphometry, dual-energy X-ray absorptiometry (DXA) and pQCT $[31,49]$. The simultaneous assessments of bone microstructure, body composition and bone/muscle-related biomarkers allowed us to provide novel insights into the relationship between bone, muscle and fat. Another strength of our work is that all mouse strains were studied at the same time under the same experimental conditions; therefore, confounding variations in diet composition, housing and handing conditions of the animals were reduced.

This study has some shortcomings. Given that our data are cross-sectional, rather than longitudinal; this work provides insights into normal growth patterns by inference. As a proxy of body composition, we calculated muscle and fat sum by summing the masses of individual muscles and fat depots. Assessment of body composition using validated methodologies would have been more accurate in determining age-related changes in muscle and fat mass [26, 50]. Mechanical testing was not directly performed to assess bone strength; nevertheless, bone microstructure has been shown to be a major determinant of bone stiffness and failure load during growth [51]. This work focused on skeletal development; therefore, we included mice at the age of rapid bone accrual (8-24 weeks). Although we were able to statistically detect maximal values in several bone microstructural parameters, we may have missed those that occurred earlier ( $<8$ weeks) or later $(>24$ weeks) than the time of observation or small time differences, which occurred between 8 and 24 weeks of age, but did not reach statistical significance.

\section{Conclusions}

This study provides a comprehensive characterization of normal skeletal development and body composition changes in three male inbred mouse strains. Our data confirm 
previous observations showing that $\mathrm{C} 3 \mathrm{H} / \mathrm{J}$ mice display the best cortical bone parameters, clarify earlier inconsistencies by demonstrating that $\mathrm{C} 57 \mathrm{BL} / 6 \mathrm{~J}$ have favorable trabecular bone parameters, and suggest that the $\mathrm{DBA} / 2 \mathrm{JRj}$ mice present with intermediate values. We further support strain differences in skeletal growth patterns; these differences affect the timing of development (i.e., C57BL/6J mice mature later than DBA/2JRj and $\mathrm{C} 3 \mathrm{H} / \mathrm{J}$ mice) and are compartment and site specific. Strain differences in body composition were observed early in the study and, albeit they were less pronounced than strain effects on skeletal phenotypes, they appeared to influence skeletal maturity. We anticipate that this work will aid in the informed selection of background strains and ages in genetic manipulations, lifestyle, pharmacological, and surgical interventions, will contribute to the interpretations of existing studies and will guide future research on the molecular and cellular regulation of peak bone mass.

Acknowledgements Open access funding provided by Medical University of Vienna. MP is the recipient of a postdoctoral Ernst Mach Fellowship (ICM-2018-10048, Austrian Agency for International Cooperation in Education and Research, Vienna, Austria). The kits for periostin analysis were kindly donated by Biomedica Medizinprodukte $\mathrm{GmbH}$, Vienna, Austria.

Author Contributions MP, USF, KW, KKS and PP participated in the study conception and design. MP and KW performed the acquisition of data. MP, USF, KW, KKS and PP participated in analysis and/or interpretation of data. MP drafted the paper; all authors reviewed and approved the final manuscript.

\section{Compliance with Ethical Standards}

Conflict of interest Katharina Kerschan-Schindl received research support and/or remuneration from Amgen GmbH, Lilly GmbH, Merck, Sharp \& Dohme GmbH, Roche Austria, and Servier Austria. Peter Pietschmann has received research support and/or remuneration from Amgen GmbH, Biomedica Medizinprodukte, BE Perfect Eagle, Fresenius Kabi GmbH, Medahead GmbH, Mylan GmbH and UCB Pharma. Maria Papageorgiou, Ursula Föger-Samwald, Katharina Wahl have no conflict of interest to declare.

Human and Animal Rights and Informed Consent All procedures were conducted in accordance with institutional and national guidelines and regulations.

Open Access This article is licensed under a Creative Commons Attribution 4.0 International License, which permits use, sharing, adaptation, distribution and reproduction in any medium or format, as long as you give appropriate credit to the original author(s) and the source, provide a link to the Creative Commons licence, and indicate if changes were made. The images or other third party material in this article are included in the article's Creative Commons licence, unless indicated otherwise in a credit line to the material. If material is not included in the article's Creative Commons licence and your intended use is not permitted by statutory regulation or exceeds the permitted use, you will need to obtain permission directly from the copyright holder. To view a copy of this licence, visit http://creativecommons.org/licenses/by/4.0/.

\section{References}

1. Weaver CM, Gordon CM, Janz KF, Kalkwarf HJ, Lappe JM, Lewis R et al (2016) The National Osteoporosis Foundation's position statement on peak bone mass development and lifestyle factors: a systematic review and implementation recommendations. Osteoporos Int 27(4):1281-1386. https://doi.org/10.1007/ s00198-015-3440-3

2. Gordon CM, Zemel BS, Wren TA, Leonard MB, Bachrach LK, Rauch F et al (2017) The determinants of peak bone mass. J Pediatr 180:261-269. https://doi.org/10.1016/j.jpeds.2016.09.056

3. Bonjour JP, Chevalley T, Ferrari S, Rizzoli R (2009) The importance and relevance of peak bone mass in the prevalence of osteoporosis. Salud Publica Mex 51(Suppl 1):S5-17

4. Sioen I, Lust E, De Henauw S, Moreno LA, Jimenez-Pavon D (2016) Associations between body composition and bone health in children and adolescents: a systematic review. Calcif Tissue Int 99(6):557-577. https://doi.org/10.1007/s00223-016-0183-x

5. Wey HE, Binkley TL, Beare TM, Wey CL, Specker BL (2011) Cross-sectional versus longitudinal associations of lean and fat mass with pQCT bone outcomes in children. J Clin Endocrinol Metab 96(1):106-114. https://doi.org/10.1210/jc.2010-0889

6. Farr JN, Amin S, LeBrasseur NK, Atkinson EJ, Achenbach SJ, McCready LK et al (2014) Body composition during childhood and adolescence: relations to bone strength and microstructure. J Clin Endocrinol Metab 99(12):4641-4648. https://doi. org/10.1210/jc.2014-1113

7. Sutter T, Toumi H, Valery A, El Hage R, Pinti A, Lespessailles E (2019) Relationships between muscle mass, strength and regional bone mineral density in young men. PLoS ONE 14(3):e0213681. https://doi.org/10.1371/journal.pone.0213681

8. Rauch F, Bailey DA, Baxter-Jones A, Mirwald R, Faulkner R (2004) The 'muscle-bone unit' during the pubertal growth spurt. Bone 34(5):771-775. https://doi.org/10.1016/j.bone.2004.01.022

9. Xu L, Nicholson P, Wang Q, Alen M, Cheng S (2009) Bone and muscle development during puberty in girls: a seven-year longitudinal study. J Bone Miner Res 24(10):1693-1698. https://doi. org/10.1359/jbmr.09040

10. Iuliano-Burns S, Mirwald RL, Bailey DA (2001) Timing and magnitude of peak height velocity and peak tissue velocities for early, average, and late maturing boys and girls. Am J Hum Biol 13(1):1-8

11. Taes YE, Lapauw B, Vanbillemont G, Bogaert V, De Bacquer $\mathrm{D}$, Zmierczak H et al (2009) Fat mass is negatively associated with cortical bone size in young healthy male siblings. J Clin Endocrinol Metab 94(7):2325-2331. https://doi.org/10.1210/ jc.2008-2501

12. Zhu K, Briffa K, Smith A, Mountain J, Briggs AM, Lye S et al (2014) Gender differences in the relationships between lean body mass, fat mass and peak bone mass in young adults. Osteoporos Int 25(5):1563-1570. https://doi.org/10.1007/s00198-014-2665-x

13. Patsch JM, Burghardt AJ, Kazakia G, Majumdar S (2011) Noninvasive imaging of bone microarchitecture. Ann N Y Acad Sci 1240:77-87. https://doi.org/10.1111/j.1749-6632.2011.06282.x

14. Beamer WG, Donahue LR, Rosen CJ, Baylink DJ (1996) Genetic variability in adult bone density among inbred strains of mice. Bone 18(5):397-403. https://doi.org/10.1016/87563282(96)00047-6

15. Chen C, Kalu DN (1999) Strain differences in bone density and calcium metabolism between $\mathrm{C} 3 \mathrm{H} / \mathrm{HeJ}$ and $\mathrm{C} 57 \mathrm{BL} / 6 \mathrm{~J}$ mice. Bone 25(4):413-420. https://doi.org/10.1016/S8756-3282(99)00185-4

16. Sabsovich I, Clark JD, Liao G, Peltz G, Lindsey DP, Jacobs CR et al (2008) Bone microstructure and its associated genetic variability in 12 inbred mouse strains: microCT study and in silico 
genome scan. Bone 42(2):439-451. https://doi.org/10.1016/j. bone.2007.09.041

17. Akhter MP, Iwaniec UT, Covey MA, Cullen DM, Kimmel DB, Recker RR (2000) Genetic variations in bone density, histomorphometry, and strength in mice. Calcif Tissue Int 67(4):337-344

18. Tommasini SM, Morgan TG, van der Meulen M, Jepsen KJ (2005) Genetic variation in structure-function relationships for the inbred mouse lumbar vertebral body. J Bone Miner Res 20(5):817-827. https://doi.org/10.1359/JBMR.041234

19. Buie HR, Moore CP, Boyd SK (2008) Postpubertal architectural developmental patterns differ between the L3 vertebra and proximal tibia in three inbred strains of mice. J Bone Miner Res 23(12):2048-2059. https://doi.org/10.1359/jbmr.080808

20. Voide R, van Lenthe GH, Muller R (2008) Bone morphometry strongly predicts cortical bone stiffness and strength, but not toughness, in inbred mouse models of high and low bone mass. J Bone Miner Res 23(8):1194-1203. https://doi.org/10.1359/jbmr.080311

21. Turner CH, Hsieh YF, Muller R, Bouxsein ML, Baylink DJ, Rosen $\mathrm{CJ}$ et al (2000) Genetic regulation of cortical and trabecular bone strength and microstructure in inbred strains of mice. J Bone Miner Res 15(6):1126-1131. https://doi.org/10.1359/jbmr.2000.15.6.1126

22. Lionikas A, Blizard DA, Gerhard GS, Vandenbergh DJ, Stout JT, Vogler GP et al (2005) Genetic determinants of weight of fast- and slow-twitch skeletal muscle in 500-day-old mice of the C57BL/6J and DBA/2J lineage. Physiol Genomics 21(2):184-192. https://doi. org/10.1152/physiolgenomics.00209.2004

23. Lionikas A, Blizard DA, Vandenbergh DJ, Stout JT, Vogler GP, McClearn GE et al (2006) Genetic determinants of weight of fastand slow-twitch skeletal muscles in old mice. Mamm Genome 17(6):615-628

24. Funkat A, Massa CM, Jovanovska V, Proietto J, Andrikopoulos S (2004) Metabolic adaptations of three inbred strains of mice (C57BL/6, DBA/2, and 129T2) in response to a high-fat diet. J Nutr 134(12):3264-3269. https://doi.org/10.1093/jn/134.12.3264

25. Reed DR, Bachmanov AA, Tordoff MG (2007) Forty mouse strain survey of body composition. Physiol Behav 91(5):593-600. https:// doi.org/10.1016/j.physbeh.2007.03.026

26. Gargiulo S, Gramanzini M, Megna R, Greco A, Albanese S, Manfredi $C$ et al (2014) Evaluation of growth patterns and body composition in C57B1/6J mice using dual energy X-ray absorptiometry. BioMed Res Int 2014:253067. https://doi.org/10.1155/2014/25306 7

27. Halloran BP, Ferguson VL, Simske SJ, Burghardt A, Venton LL, Majumdar S (2002) Changes in bone structure and mass with advancing age in the male C57BL/6J mouse. J Bone Miner Res 17(6):1044-1050. https://doi.org/10.1359/jbmr.2002.17.6.1044

28. Ferguson VL, Ayers RA, Bateman TA, Simske SJ (2003) Bone development and age-related bone loss in male C57BL/6J mice. Bone 33(3):387-398. https://doi.org/10.1016/S8756-3282(03)00199 $-6$

29. Glatt V, Canalis E, Stadmeyer L, Bouxsein ML (2007) Agerelated changes in trabecular architecture differ in female and male C57BL/6J mice. J Bone Miner Res 22(8):1197-1207. https://doi. org/10.1359/jbmr.070507

30. Sheng MH, Baylink DJ, Beamer WG, Donahue LR, Rosen CJ, Lau $\mathrm{KH}$ et al (1999) Histomorphometric studies show that bone formation and bone mineral apposition rates are greater in $\mathrm{C} 3 \mathrm{H} / \mathrm{HeJ}$ (highdensity) than C57BL/6J (low-density) mice during growth. Bone 25(4):421-429. https://doi.org/10.1016/S8756-3282(99)00184-2

31. Bouxsein ML, Boyd SK, Christiansen BA, Guldberg RE, Jepsen KJ, Muller R (2010) Guidelines for assessment of bone microstructure in rodents using micro-computed tomography. J Bone Miner Res 25(7):1468-1486. https://doi.org/10.1002/jbmr.141

32. Brotto M, Bonewald L (2015) Bone and muscle: Interactions beyond mechanical. Bone 80:109-114. https://doi.org/10.1016/j. bone.2015.02.010
33. Elkasrawy MN, Hamrick MW (2010) Myostatin (GDF-8) as a key factor linking muscle mass and bone structure. J Musculoskelet Neuronal Interact 10(1):56-63

34. Hamrick MW, Shi X, Zhang W, Pennington C, Thakore H, Haque M et al (2007) Loss of myostatin (GDF8) function increases osteogenic differentiation of bone marrow-derived mesenchymal stem cells but the osteogenic effect is ablated with unloading. Bone 40(6):1544 1553. https://doi.org/10.1016/j.bone.2007.02.012

35. Bonnet N, Garnero P, Ferrari S (2016) Periostin action in bone. Mol Cell Endocrinol 432:75-82. https://doi.org/10.1016/j. mce.2015.12.014

36. Ozdemir C, Akpulat U, Sharafi P, Yildiz Y, Onbasilar I, Kocaefe C (2014) Periostin is temporally expressed as an extracellular matrix component in skeletal muscle regeneration and differentiation. Gene 553(2):130-139. https://doi.org/10.1016/j.gene.2014.10.014

37. Silva MJ, Eekhoff JD, Patel T, Kenney-Hunt JP, Brodt MD, StegerMay K et al (2019) Effects of high-fat diet and body mass on bone morphology and mechanical properties in 1100 advanced intercross mice. J Bone Miner Res 34(4):711-725

38. Sheng MH, Baylink DJ, Beamer WG, Donahue LR, Lau KH, Wergedal JE (2002) Regulation of bone volume is different in the metaphyses of the femur and vertebra of $\mathrm{C} 3 \mathrm{H} / \mathrm{HeJ}$ and $\mathrm{C} 57 \mathrm{BL} / 6 \mathrm{~J}$ mice. Bone 30(3):486-491

39. Brodt MD, Ellis CB, Silya MJ (1999) Growing C57 mice increase whole bone strength by increasing bone size and material strength. J Bone Miner Res. https://doi.org/10.1359/jbmr.1999.14.12.2159

40. Frost HM (2003) Bone's mechanostat: a 2003 update. Anat Rec A 275(2):1081-1101. https://doi.org/10.1002/ar.a.10119

41. Kodama Y, Dimai HP, Wergedal J, Sheng M, Malpe R, Kutilek $S$ et al (1999) Cortical tibial bone volume in two strains of mice: effects of sciatic neurectomy and genetic regulation of bone response to mechanical loading. Bone 25(2):183-190. https://doi. org/10.1016/S8756-3282(99)00155-6

42. Kodama Y, Umemura Y, Nagasawa S, Beamer WG, Donahue LR, Rosen CR et al (2000) Exercise and mechanical loading increase periosteal bone formation and whole bone strength in C57BL/6J mice but not in C3H/Hej mice. Calcif Tissue Int 66(4):298-306. https://doi.org/10.1007/s002230010060

43. Parfitt AM (2004) The attainment of peak bone mass: what is the relationship between muscle growth and bone growth? Bone 34(5):767-770. https://doi.org/10.1016/j.bone.2004.01.023

44. Elkina Y, von Haehling S, Anker SD, Springer J (2011) The role of myostatin in muscle wasting: an overview. J Cachex Sarcopenia Muscle 2(3):143-151. https://doi.org/10.1007/s13539-011-0035-5

45. Bonnet N, Standley KN, Bianchi EN, Stadelmann V, Foti M, Conway SJ et al (2009) The matricellular protein periostin is required for sost inhibition and the anabolic response to mechanical loading and physical activity. J Biol Chem 284(51):35939-35950. https:// doi.org/10.1074/jbc.M109.060335

46. Rios H, Koushik SV, Wang H, Wang J, Zhou HM, Lindsley A et al (2005) Periostin null mice exhibit dwarfism, incisor enamel defects, and an early-onset periodontal disease-like phenotype. Mol Cell Biol 25(24):11131-11144. https://doi.org/10.1128/MCB.25.24.11131 $-11144.2005$

47. Reid IR (2010) Fat and bone. Arch Biochem Biophys 503(1):20-27. https://doi.org/10.1016/j.abb.2010.06.027

48. Glass NA, Torner JC, Letuchy EM, Burns TL, Janz KF, Eichenberger Gilmore JM et al (2016) The relationship between greater prepubertal adiposity, subsequent age of maturation, and bone strength during adolescence. J Bone Miner Res 31(7):1455-1465. https://doi.org/10.1002/jbmr.2809

49. Schmidt C, Priemel M, Kohler T, Weusten A, Muller R, Amling M et al (2003) Precision and accuracy of peripheral quantitative computed tomography (pQCT) in the mouse skeleton compared with histology and microcomputed tomography (microCT). J Bone Miner Res 18(8):1486-1496. https://doi.org/10.1359/jbmr.2003.18.8.1486 
50. Halldorsdottir S, Carmody J, Boozer CN, Leduc CA, Leibel RL (2009) Reproducibility and accuracy of body composition assessments in mice by dual energy $x$-ray absorptiometry and time domain nuclear magnetic resonance. Int J Body Compos Res 7(4):147-154

51. Sumner DR, Andriacchi TP (1996) Adaptation to differential loading: comparison of growth-related changes in cross-sectional properties of the human femur and humerus. Bone 19(2):121-126. https:// doi.org/10.1016/8756-3282(96)00166-4
Publisher's Note Springer Nature remains neutral with regard to jurisdictional claims in published maps and institutional affiliations. 